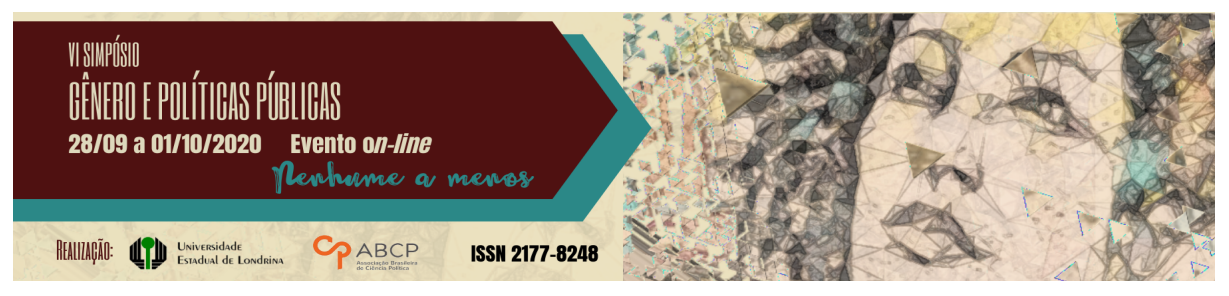

\title{
A instituição Missão Paz e as refugiadas: combate às explorações e às discriminações, inserção no mercado de trabalho brasileiro e integração local
}

\author{
Maíra Furquim Lunardello ${ }^{1}$
}

\begin{abstract}
Resumo
O presente relato se propõe a sistematizar a experiência vivenciada com a visita à instituição Missão Paz, em 2017, que tem como finalidade fornecer assistência, em diversas esferas, a migrantes no Brasil. A visita à instituição revela informações acerca do enfrentamento às discriminações e às explorações que vitimizam as refugiadas, com o propósito de inseri-las no mercado de trabalho brasileiro em condições dignas e, assim, integrá-las no país. Como procedimento metodológico, realiza-se uma pesquisa de campo na referida instituição, participando-se de uma visita guiada pelos seus espaços físicos e de diálogos com um dos seus diretores e com as profissionais dos eixos jurídico e do trabalho. Por meio da visita, alcança-se resultados quanto à importância da instituição para o acolhimento das refugiadas no país e como o embate contra as discriminações de gênero e as explorações que assolam estas mulheres faz-se necessário para inseri-las no mercado de trabalho de forma digna e, deste modo, integrá-las de fato no país.
\end{abstract}

Palavras-chave: refugiadas; instituição missão paz; trabalho.

\section{The institution Missão Paz and the female refugees: the action against exploitations and discriminations, insertion in the Brazilian labor market and local integration}

\section{Abstract}

\footnotetext{
1 Advogada, graduada em direito pela Faculdade de Direito de Franca. E-mail: mairafulu@gmail.com
}

GT 12 - Gênero, refúgio e migrações 
This report proposes to systematize the experience lived with the visit to the Missão Paz institution, in 2017, which aims to provide assistance, in various aspects, to migrants in Brazil. The visit to the institution reveals information about the combat against the discriminations and exploitations that victimize female refugees, with the purpose of inserting them into the Brazilian decent lobar market, and, thus, integrate then into the country. As methodology, realize a field research at the institution, taking part in a guided tour of its physicals spaces and dialogues with one of its directors and work and legal professionals. Through the visit, results were achieved in relation to the importance of the institution for the receptions of female refugees in the country and how the struggle against gender discrimination and exploitations that devastate these women is necessary to insert them into the decent labor market and, in this way, effectively integrate them.

Key-words: female refugees; institution missão paz; work.

Considerando o contexto contemporâneo de mobilidade humana e o Brasil como um país receptor de mulheres em condição de refúgio, este relato pretende sistematizar a experiência vivenciada em uma visita à instituição filantrópica Missão Paz, na cidade de São Paulo, que fornece acolhimento e assistência a refugiadas, bem como revelar os mecanismos adotados pela instituição para auxiliar estas mulheres a enfrentarem as discriminações e as explorações que as vitimizam, com o propósito de inseri-las no mercado de trabalho brasileiro em condições dignas e, assim, integrá-las de fato no país.

O relato, então, se propõe a ordenar esta experiência com base nas formulações de Oscar Jara, que, assim, dispõe:

Uma característica essencial consiste em que a sistematização reconstrua o que sucedeu nesses processos, faz-se uma recuperação histórica da experiência; também se ordenam os distintos elementos que sucederam ao longo desses processos complexos, dinâmicos, como sucederam e como se perceberam e viveram nesse momento (JARA, 2006, p. 229).

Por conseguinte, a visita à instituição tinha, a princípio, o propósito de, além de obter dados acerca dos processos de acolhimento 
e assistência prestados às refugiadas residentes no Brasil, realizar entrevistas com estas mulheres com o intuito de coletar informações sobre suas perspectivas em relação ao acolhimento oferecido pelo governo brasileiro, a existência de discriminação por parte da sociedade brasileira, os principais obstáculos vivenciados por refugiadas no Brasil, a receptividade do mercado de trabalho brasileiro para mulheres em condição de refúgio e, por fim, a ocorrência de violações aos direitos das refugiadas nos locais de trabalho.

Para realizar as entrevistas almejadas, foram elaborados um questionário e um termo de consentimento a fim de respeitar a identidade e dignidade destas mulheres. $O$ referido questionário continha perguntas relativas a como as refugiadas acolhidas na Missão Paz visualizavam a concepção da sociedade brasileira sobre o refúgio, quais eram os maiores desafios para estas mulheres no território e no mercado de trabalho brasileiro.

Importante pontuar que, antes de ocorrer o deslocamento até a instituição, houve um agendamento prévio, via e-mail, para participar de uma visita guiada pelos espaços da Missão Paz, já que, somente após a realização desta visita, permite-se que sejam realizadas entrevistas com as acolhidas no pátio da entidade.

A visita ocorreu, então, no dia 25 de outubro de 2017. Neste dia, a experiência iniciou-se com uma apresentação da história da Missão Paz e dos serviços assistenciais prestados pela Casa do Migrante, que dispõe de cento e dez vagas para migrantes com o fornecimento de alimentação, oferece assistência jurídica, auxílio para a obtenção de documentos, atendimento social, psicológico, educacional e de saúde, realiza a mediação entre empresas e migrantes e atua para o fortalecimento de políticas migratórias que atendam aos direitos humanos destes grupos.

Em seguida, visitou-se, guiada por um profissional, os espaços físicos da entidade, como a Casa do Migrante, o Centro de Estudos Migratórios (CEM), que coordena a publicação da revista TRAVESSIA, 
e a Paróquia Nossa Senhora da Paz. Por último, houve um diálogo com um dos diretores da instituição, padre Paolo Parise.

Neste diálogo, foram feitas indagações sobre como as mulheres refugiadas estão inseridas no mercado de trabalho brasileiro e se estas são vítimas de discriminações. Em resposta, elucidou-se que, apesar de muitas refugiadas possuírem formação superior, são contratadas no Brasil para trabalharem em cozinhas de restaurantes, oficinas de costura e em serviços de limpeza e, muitas vezes, há uma superexploração do seu trabalho.

No tocante às perguntas em relação às discriminações, o profissional explicitou que estas mulheres são discriminadas por estarem em condição de refúgio, sendo que as mulheres negras e mulçumanas são ainda mais atingidas e apresentam maiores dificuldades para obter trabalhos, inclusive, relatou que algumas empresas exigem que as mulçumanas retirem o hijab para serem contratadas.

Após o diálogo, houve o encerramento da visita guiada e foi disponibilizada a autorização para efetuar as entrevistas com mulheres refugiadas no pátio da instituição. Todavia, mesmo com a referida autorização, não foi possível executar as entrevistas, pois não foram localizadas no dia 25, ao menos de acordo com o contato estabelecido pela pesquisadora com as pessoas que se encontravam no pátio da Missão Paz, mulheres em condição de refúgio para serem consultadas sobre o interesse em participar da entrevista.

No dia 25, havia no pátio da entidade, em sua maioria, homens migrantes e poucas mulheres migrantes, sendo que nenhuma destas afirmaram estar em condição de refúgio. Acredita-se que não foi possível localizar alguma mulher refugiada que pudesse ser consultada sobre a participação na entrevista, porque a instituição permite, conforme informado pelo profissional que guiou a visita, que as mulheres acolhidas permaneçam dentro da Casa do Migrante durante 
o período diurno e noturno, mas proíbe-se que os homens permaneçam durante o período diurno, com algumas exceções.

Como o objetivo central da pesquisa não foi alcançado no dia 25, tentou-se realizar as entrevistas no dia seguinte, 26 de outubro, porém, realmente, não ocorreu como o almejado, já que, novamente, não foram localizadas mulheres que se enquadravam nos requisitos referentes ao propósito da entrevista.

Entretanto, neste dia, foi possível conversar diretamente com a profissional responsável pelo eixo jurídico da instituição, que reiterou as informações obtidas no diálogo realizado no dia anterior quanto às discriminações sofridas pelas refugiadas no Brasil e em relação a forma como estas mulheres estão inseridas no mercado de trabalho brasileiro.

Ademais, esta experiência prosperou com a autorização da profissional do eixo do trabalho para participar de uma reunião com proprietários de empresas interessados na contratação de migrantes, sendo que, por meio desta reunião, foi possível observar como a instituição orienta estes empresários no sentido de promover o respeito à dignidade dos imigrantes e refugiados.

Sendo assim, apesar das entrevistas não terem sido realizadas, durante a visita monitorada, o diálogo com o padre Paolo Parise e mediante o contato com as profissionais dos eixos jurídico e do trabalho da instituição, obteve-se dados fundamentais em relação ao cenário trabalhista brasileiro para pessoas em condição de refúgio, sobretudo, no que concerne às dificuldades enfrentadas pelas mulheres refugiadas, e às discriminações sofridas por parte dos autóctones, fazendo-se possível, assim, formular aprendizados e pensar em linhas de ação que possibilitem a reestruturação do contexto atual em que estão inseridas as refugiadas no Brasil.

Neste sentido, aduz Oscar Jara:

Todo esse tema da obtenção de lições da própria experiência, que devem servir à própria experiência, significa um paradigma epistemológico; supõe uma 
maneira de ver o mundo, de situarmo-nos antes o mundo, de situarmo-nos ante a compreensão e a transformação do mundo como parte de um mesmo movimento. Então, reconstruir, ordenar o acontecido, para compreender e interpretar o acontecido e para poder então transformar e tirar lições dessa própria experiência, supõe uma postura epistemológica, social, política e cultural. É muito mais que um método (JARA, 2006, p. 230).

No que diz respeito a estes dados, apurou-se que as imposições de gênero, que condicionam as mulheres a agirem de determinada forma e a ocuparem papéis predeterminados dentro de uma sociedade, faz com que as refugiadas sejam submetidas a trabalhos que consistem em uma extensão dos serviços domésticos, apesar de terem ensino superior e experiência em diversas áreas, além destes trabalhos serem mal remunerados e violarem o acesso ao trabalho digno assegurado pelas Lei $n^{\circ} 9.474 / 1997$ e Lei n ${ }^{\circ} 13.445 / 2017$.

Outrossim, constatou-se que a sociedade brasileira possui uma concepção xenofóbica em relação a mulheres em condição de refúgio, que é agravada pela perspectiva de raça e religiosa, influenciando, assim, no acolhimento e na integração local de mulheres refugiadas no país.

Desta feita, conforme a experiência relatada, infere-se que a Missão Paz exerce papel preponderante na sociedade civil, assim como outras instituições, no acolhimento e na integração de refugiadas no país, além de atuar com incidência política pela proteção da dignidade destas pessoas. Ou seja, supre a ausência do governo brasileiro na implementação de políticas públicas que efetivamente integrem as refugiadas no contexto nacional.

Por fim, compreende-se que a referida instituição busca auxiliar mulheres em condição de refúgio a efetivarem o acesso ao trabalho digno, para que, desta forma, possam ser integradas de fato no território brasileiro e, assim, obterem acesso a demais diretos que lhes são garantidos, como, por exemplo, moradia, educação e saúde. 
Portanto, ao sistematizar a experiência relatada, torna-se possível compreender o cenário vivenciado pelas refugiadas no país e, como produto desta sistematização, obter resultados que apontam a importância de uma instituição da sociedade civil para o acolhimento deste grupo e como o embate contra as discriminações de gênero e as explorações que assolam estas mulheres faz-se necessário para inserilas no mercado de trabalho brasileiro de forma digna e, deste modo, integrá-las de fato no país.

\section{Referências}

BRASIL. Lei $n^{\circ} 9.474$ de 22 de julho de 1997. Define mecanismos para a implementação do Estatuto dos Refugiados de 1951, e determina outras providências. Diário Oficial da União, Poder Executivo, Brasília, DF, 23 jul. 1997. Disponível em: https:/ / www2.camara.leg.br/legin/fed/lei/1997/lei-9474-22-julho1997-365390-publicacaooriginal-1-pl.html. Acesso em: 13 fev. 2020.

BRASIL. Lei $n^{0} 13.445$ de 24 de maio de 2017. Institui a Lei de Migração. Diário Oficial da União, Poder Executivo, Brasília, DF, 24 maio 2017. Disponível em: http://www.planalto.gov.br/ccivil_03/_Ato20152018/2017/Lei/L13445.htm. Acesso em: 17 fev. 2020.

HOLLIDAY, Oscar Jara. Sistematização das experiências: algumas apreciações. In: BRANDÃO, Carlos Rodrigues; STRECK, Danilo R. Pesquisa participante: a partilha do saber. Aparecida: Ideias \& Letras, 2006. 